\title{
Sibimbel: Aplikasi Android untuk Bimbingan Belajar Yayasan Meldita Class
}

\author{
Mauldy Laya, Nadya Felinda Winarto \\ Teknik Informatika \\ Politeknik Negeri Jakarta \\ Depok, Jawa Barat, Indonesia \\ dylaya@gmail.com,nadyafelinda@gmail.com
}

Diterima: 2 April 2018. Disetujui: 21 April 2018. Dipublikasikan: Mei 2018

\begin{abstract}
Abstrak - Yayasan Meldita Class berdiri sejak tahun 2007 dan fokus kepada bimbingan belajar privat yang menyebarkan gurunya di daerah Jakarta Timur dan Bekasi. Semua sistem kelola kegiatan belajar mengajar masih manual sehingga memicu banyaknya masalah. Permasalahan perubahan jadwal mengajar yang tidak sampai kepada salah satu pihak antara guru dengan orangtua atau wali murid, kurangnya transparansi terkait pembayaran mengajar terhadap guru, tidak adanya tolak ukur baik bagi orangtua atau wali murid, guru, dan yayasan untuk melihat perkembangan murid. Aplikasi bimbingan belajar berbasis android dibangun untuk mengatasi masalahmasalah yang ada pada Yayasan Meldita Class sehingga memudahkan orangtua atau wali murid, guru, dan yayasan untuk berkomunikasi dengan baik dan lancar. Aplikasi ini dibangun menggunakan metode Guideliness for Rapid Application Engineering (GRAPPLE). Orangtua dan guru dapat mengajukan perubahan jadwal mengajar melalui aplikasi ini. Platform android dipakai agar aplikasi lebih mudah dan fleksibel untuk digunakan dimanapun dan kapanpun pengguna berada. Dengan adanya aplikasi ini dapat mempermudah guru, orangtua atau wali murid untuk melihat jadwal, memudahkan guru untuk melakukan rekap absen, dan latihan kuis bagi siswa. Aplikasi diuji menggunakan metode black-box dan user acceptance testing. Hasil pengujian terhadap 9 responden, yaitu 3 orang guru, 3 orang orangtua atau wali murid, dan 3 murid menyatakan aplikasi dapat dipakai oleh Yayasan Meldita Class.
\end{abstract}

Kata Kunci: aplikasi android, guideliness for rapid application engineering (GRAPPLE), bimbingan belajar.

\section{PENDAHULUAN}

Bimbingan belajar merupakan proses pemberian bantuan kepada murid dalam memecahkan kesulitan-kesulitan yang berhubungan dengan masalah belajar. Tujuan bimbingan belajar adalah membantu murid-murid agar mendapatkan penyesuaian yang baik dalam situasi belajar [1].
Yayasan Meldita Class adalah salah satu tempat bimbingan belajar yang berada di daerah Jakarta Timur. Yayasan ini telah berdiri sejak tahun 2007. Ada tujuh guru dan puluhan murid yang tersebar di wilayah Bekasi dan Jakarta Timur. Yayasan sudah mempunyai sistem sendiri dalam proses belajar mengajar, namun masih manual dan belum terintegrasi dengan baik. Sering terjadi salah komunikasi seperti perubahan jadwal dari guru yang tidak sampai ke orangtua atau wali murid melalui pihak yayasan, begitu pun sebaliknya, laporan yang berkaitan dengan honor guru kurang tertata rapi dan tidak adanya transparansi rincian pembayaran, tidak adanya informasi dari pihak yayasan terhadap orangtua atau wali murid dan guru terkait perkembangan murid di setiap semesternya, dan tidak adanya media untuk orangtua atau wali murid dalam memberikan umpan balik seperti memberikan penilaian dalam hal kinerja guru.

Untuk mengatasi masalah-masalah tersebut, maka dibuat aplikasi Android yang dapat digunakan oleh guru, orangtua atau wali murid, dan murid. Salah satu keuntungan aplikasi ini adalah agar guru dan orangtua atau wali murid dapat mengajukan perubahan jadwal les dimanapun dan kapanpun mereka berada, serta murid dapat mengerjakan kuis online dengan fleksibel. Platform android dipakai agar aplikasi lebih mudah dan fleksibel untuk digunakan dimanapun dan kapanpun pengguna berada. Android merupakan platform yang lengkap, terbuka, dan bebas [2].

Aplikasi sejenis seperti FindMyTutor merupakan aplikasi android yang dikembangkan di Thailand untuk murid dan pengajar yang dapat digunakan secara gratis. Fungsi utama adalah rekomendasi program agensi seperti jadwal kelas, komunitas web board, dan pesan pribadi. Selain itu juga ada video perkenalan personil pengajar dan fungsi mencocokkan pengajar dan murid berdasarkan lokasi, jenis kelamin, peringkat dan usia [3]. 


\section{METODOLOGI}

Metode yang digunakan pada pengembangan aplikasi SiBimBel adalah metode Guideliness for Rapid Application Engineering (GRAPPLE). Metode GRAPPLE menggunakan konsep berbasis obyek dengan pemodelan yang berfokus pada pengembangan modul menggunakan Unified Modelling Language (UML). Adapun tahapantahapan pengerjaan yang dilakukan adalah requirement gathering, analysis, design, development dan deployment [4][5].

Tahap requirement gathering yaitu mengambil informasi lengkap dari pengguna tentang sistem yang akan dibangun dengan wawancara maupun kuesioner. Wawancara dilakukan langsung dengan pengguna yang terlibat. Tahap analysis dilakukan pengkajian permasalahan yang sudah didapatkan dari hasil wawancara dan kuesioner. Dari hasil pengkajian tersebut, selanjutnya melakukan analisa untuk solusinya. Tahap design dilakukan perancangan dari model serta diagram. Diagramdiagram tersebut antara lain akan menunjukkan proses dan aktifitas pada sistem, rancangan dan penyimpanan data, serta rancangan antarmuka.

Tahap development merupakan membangun kode program dan user interface yang menggunakan bahasa pemrograman java dengan sistem operasi android. Pengujian program dan dokumentasi sistem dilakukan pada tahap ini. Tahap terakhir adalah deployment yang merupakan tahap pendistribusian produk yang dihasilkan kepada pengguna. Proses instalasi aplikasi dilakukan pada saat pihak yayasan memberikan kepada orangtua atau wali murid dan guru dalam bentuk berkas .apk.

\section{HASIL DAN PEMBAHASAN}

Berdasarkan hasil wawancara dan kuesioner yang dilakukan, terdapat beberapa masalah yang ditemui, diantaranya :

- Hampir semua orangtua atau wali murid mengalami kesulitan dalam komunikasi dengan pihak guru les pada saat ingin melakukan perubahan jadwal les.

- Tidak adanya ruang bagi orangtua atau wali murid jika ingin memberikan komentar terhadap kinerja guru les.

- Tidak adanya tolak ukur bagi pihak yayasan untuk melihat perkembangan belajar murid disetiap semesternya.

- Rata-rata guru les mendapatkan jadwal mengajar mereka hanya pada setiap awal semester, membuat guru merasa kesulitan jika lupa dengan jadwal mengajarnya.
- Waktu pembayaran honor mengajar guru les yang tidak menentu dan tidak adanya rincian kepada guru les dari pihak yayasan.

- Pihak yayasan mengalami kesulitan dalam pengumpulan laporan mengajar yang sudah diisi oleh guru les disetiap pertemuannya.

Dari hasil analisa masalah, maka didapatkan suatu gambaran mengenai kebutuhan aplikasi, yaitu :

- Pengajuan perubahan jadwal (Menu Jadwal). Fitur ini berguna untuk melakukan pengajuan perubahan jadwal jika tidak sesuai dengan murid. Pengajuan perubahan jadwal dapat dilakukan oleh guru dan orangtua atau wali murid.

- Memberikan komentar terhadap laporan atau kinerja guru (Menu Laporan). Fitur ini berguna bagi para orangtua atau wali murid untuk memberikan penilaian terhadap kinerja mengajar guru les. Fitur ini hanya tersedia untuk orangtua atau wali murid, terdapat pada menu laporan.

- Melihat perkembangan murid (Menu Perkembangan Murid dan Kuis Online). Fitur ini berguna bagi guru les dan orangtua atau wali murid untuk melihat perkembangan murid. Pihak yayasan membuat fitur kuis online yang berfungsi sebagai tolak ukur dalam melihat perkembangan murid.

- Pencarian jadwal mengajar (Menu Jadwal). Fitur ini ditujukan bagi guru les dalam melihat jadwal mengajar yang dimilikinya dan bagi orangtua atau wali murid dalam melihat jadwal les yang dimiliki oleh anaknya.

- Melihat rincian laporan honor (Menu Laporan). Fitur ini berguna bagi guru les untuk melihat secara rinci pembayaran mengajar yang didapat setiap bulannya.

- Mengisi laporan pertemuan (Menu Absen). Fitur ini ditujukan bagi guru les untuk mengisi laporan setiap selesai mengajar dengan mengisi sesuai field yang telah disediakan sistem.

Berdasarkan hasil dari tahapan sebelumnya maka didapatkan hasil analisis solusi dari data dan informasi yang diperoleh pada tahapan requirement gathering serta ilustrasi dari proses bisnis seperti telihat pada Tabel 1.

TABEL 1. HASIL ANALISA SOLUSI

\begin{tabular}{|c|c|c|c|}
\hline No & $\begin{array}{l}\text { Harapan } \\
\text { Pengguna }\end{array}$ & Kondisi Saat Ini & Solusi \\
\hline 1 & $\begin{array}{l}\text { Dapat } \\
\text { melakukan } \\
\text { perubahan } \\
\text { jadwal } \\
\text { dengan } \\
\text { cepat. }\end{array}$ & $\begin{array}{lr}\text { Guru les } & \text { harus } \\
\text { menghubungi } & \text { pihak } \\
\text { yayasan terlebih } \\
\text { dahulu jika ingin } \\
\text { melakukan } \\
\text { perubahan jadwal, } \\
\text { setelahnya pihak } \\
\text { yayasan harus } \\
\text { menghubungi pihak } \\
\text { orangtua atau }\end{array}$ & $\begin{array}{l}\text { Menyediakan fitur } \\
\text { Ajukan Perubahan } \\
\text { Jadwal pada menu } \\
\text { Jadwal yang } \\
\text { berfungsi untuk } \\
\text { mengajukan } \\
\text { perubahan jadwal } \\
\text { tanpa harus } \\
\text { menghubungi } \\
\text { pihak yayasan }\end{array}$ \\
\hline
\end{tabular}




\begin{tabular}{|c|c|c|c|}
\hline & & $\begin{array}{lr}\text { murid } & \text { untuk } \\
\text { kepastian jadwal les. } \\
\text { Jika sudah ada } \\
\text { kepastian, maka } \\
\text { pihak yayasan akan } \\
\text { menghubungi guru } \\
\text { les terkait fiksasi } \\
\text { jadwal les. Begitu } \\
\text { pun sebaliknya. }\end{array}$ & terlebih dahulu. \\
\hline 2 & $\begin{array}{l}\text { Orangtua } \\
\text { atau wali } \\
\text { murid dapat } \\
\text { memberika } \\
\mathrm{n} \text { umpan } \\
\text { balik } \\
\text { seperti } \\
\text { berkomenta } \\
\mathrm{r} \text { dan } \\
\text { memberi } \\
\text { rating } \\
\text { kepada } \\
\text { kinerja } \\
\text { mengajar } \\
\text { guru. }\end{array}$ & $\begin{array}{l}\text { Orangtua atau wali } \\
\text { murid tidak bisa } \\
\text { memberi komentar } \\
\text { dan tidak bisa } \\
\text { memberi penilaian } \\
\text { terhadap kinerja } \\
\text { mengajar guru. }\end{array}$ & $\begin{array}{lr}\text { Tersedia fitur } \\
\text { umpan balik bagi } \\
\text { orangtua atau wali } \\
\text { murid yang } \\
\text { tersedia pada } \\
\text { menu Laporan. }\end{array}$ \\
\hline 3 & $\begin{array}{l}\text { Baik } \\
\text { orangtua } \\
\text { atau wali } \\
\text { murid, guru } \\
\text { les, dan } \\
\text { pihak dapat } \\
\text { melihat } \\
\text { perkemban } \\
\text { gan murid } \\
\text { yang } \\
\text { ditampilkan } \\
\text { dalam } \\
\text { bentuk } \\
\text { grafik. }\end{array}$ & 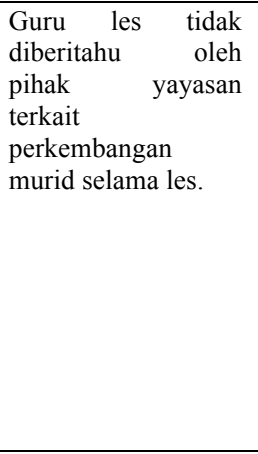 & $\begin{array}{l}\text { Lewat fitur kuis } \\
\text { online dan menu } \\
\text { Perkembangan } \\
\text { Murid, baik } \\
\text { orangtua atau wali } \\
\text { murid maupun } \\
\text { guru les dapat } \\
\text { mengetahui } \\
\text { perkembangan } \\
\text { prestasi murid. }\end{array}$ \\
\hline 4 & $\begin{array}{l}\text { Guru les } \\
\text { dan } \\
\text { orangtua } \\
\text { atau wali } \\
\text { murid ingin } \\
\text { leluasa } \\
\text { mencari } \\
\text { jadwal baik } \\
\text { jadwal } \\
\text { yang rutin } \\
\text { maupun } \\
\text { jadwal } \\
\text { yang sudah } \\
\text { diubah. }\end{array}$ & $\begin{array}{l}\text { Jadwal hanya } \\
\text { diberitahukan } \\
\text { kepada guru les dan } \\
\text { orangtua atau wali } \\
\text { murid oleh pihak } \\
\text { yayasan hanya pada } \\
\text { saat awal semester. }\end{array}$ & $\begin{array}{l}\text { Sistem } \\
\text { menyediakan fitur } \\
\text { menu Jadwal } \\
\text { untuk menyimpan } \\
\text { data jadwal } \\
\text { mengajar guru les. }\end{array}$ \\
\hline 5 & $\begin{array}{l}\text { Guru les } \\
\text { mendapatka } \\
\mathrm{n} \quad \text { rincian } \\
\text { terkait } \\
\text { honor } \\
\text { mengajar. }\end{array}$ & $\begin{array}{l}\text { Pihak yayasan hanya } \\
\text { memberikan total } \\
\text { honor mengajar } \\
\text { kepada guru les } \\
\text { tanpa memberikan } \\
\text { rinciannya. }\end{array}$ & $\begin{array}{lr}\text { Adanya } & \text { fitur } \\
\text { menu Laporan } \\
\text { Honor, guru les } \\
\text { tidak perlu } \\
\text { khawatir } \\
\text { mengenai rincian } \\
\text { pembayaran } \\
\text { karena pada saat } \\
\text { pemberian honor, } \\
\text { pihak yayasan } \\
\text { akan menyertakan } \\
\text { rincian } \\
\text { pembayarannya. }\end{array}$ \\
\hline 6 & $\begin{array}{l}\text { Pengisian } \\
\text { laporan } \\
\text { yang diisi } \\
\text { rutin } \\
\text { setelah } \\
\text { mengajar } \\
\text { dan } \\
\end{array}$ & $\begin{array}{lr}\text { Pihak } & \text { yayasan } \\
\text { kesulitan dalam } & \text { mengumpulkan } \\
\text { laporan mengajar } \\
\text { yang telah diisi oleh } \\
\text { guru les karena } \\
\text { pengisian laporan }\end{array}$ & $\begin{array}{l}\text { Sistem } \\
\text { menyediakan fitur } \\
\text { menu absen pada } \\
\text { user guru les yang } \\
\text { berfungsi sebagai } \\
\text { tempat mengisi } \\
\text { laporan yang akan }\end{array}$ \\
\hline
\end{tabular}

\begin{tabular}{|l|l|l|lr|}
\hline & diterima & diisi di kertas & langsung diterima \\
secara & selembar sehingga & oleh pihak \\
cepat oleh & $\begin{array}{l}\text { rentan rusak dan } \\
\text { pihak } \\
\text { yayasan. }\end{array}$ & hilang. & & \\
\hline
\end{tabular}

Hasil tahapan design, didapatkan sebuah gambaran aplikasi seperti yang ditunjukkan pada diagram use case pada Gambar 1 dan detil pengguna pada Tabel 2. Diagram use case merupakan pemodelan untuk kelakuan sistem informasi yang akan dibuat. Use case mendeskripsikan sebuah interaksi antara satu atau lebih aktor dengan sistem informasi yang akan dibuat [6].

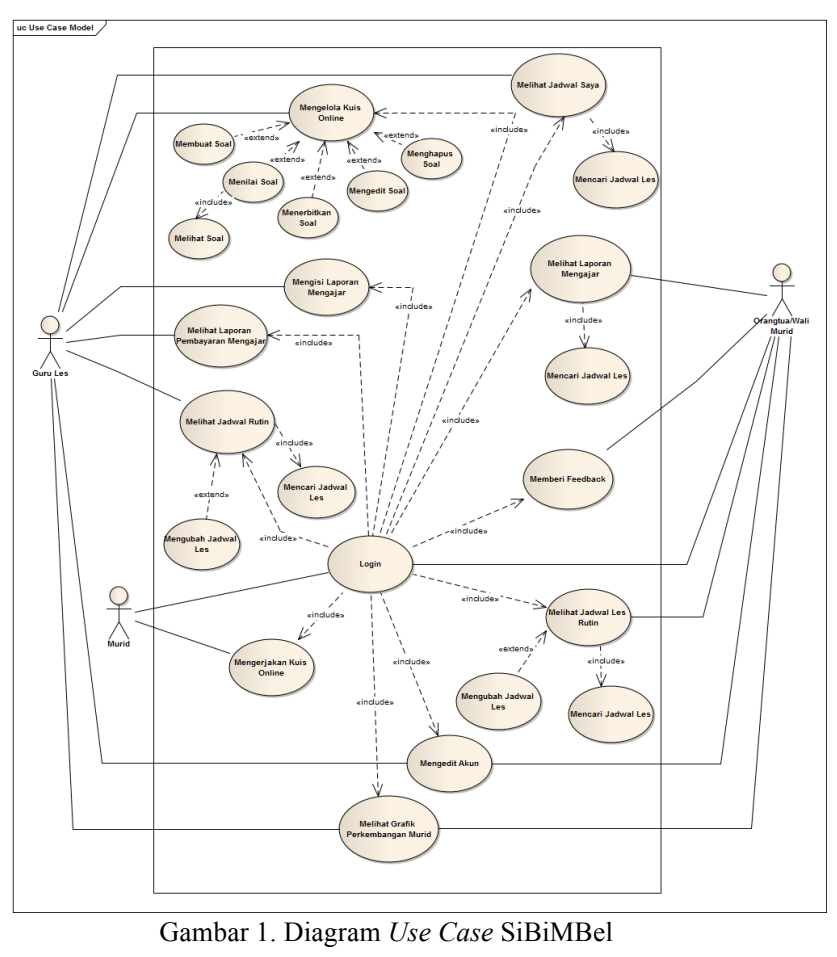

TABEL 2. DETAIL AKTOR DIAGRAM USE CASE

\begin{tabular}{|l|l|}
\hline Aktor & Deskripsi \\
\hline Guru Les & $\begin{array}{l}\text { Guru les dapat melihat profil orangtua dan murid, } \\
\text { dapat melihat laporan pembayaran mengajar, dapat } \\
\text { mengelola laporan mengajar seperti menghapus } \\
\text { laporan, mengedit laporan, dan melihat laporan } \\
\text { mengajar, dapat melihat, mencari, dan mengubah } \\
\text { jadwal les, dapat melihat profil yayasan, mengedit } \\
\text { akun, serta melihat perkembangan murid. }\end{array}$ \\
\hline $\begin{array}{l}\text { Orangtua } \\
\text { atau wali } \\
\text { murid }\end{array}$ & $\begin{array}{l}\text { Orangtua atau wali murid dapat melihat laporan } \\
\text { yang sudah dibuat oleh guru les, setelahnya } \\
\text { orangtua atau wali murid dapat memberikan } \\
\text { umpan balik berupa komentar. Orangtua atau wali } \\
\text { murid juga dapat melihat, mencari, dan } \\
\text { mengajukan perubahan jadwal. Orangtua atau } \\
\text { wali murid juga dapat melihat profil yayasan, } \\
\text { mengedit akun, dan melihat perkembangan murid, } \\
\text { serta dapat melihat profil guru. }\end{array}$ \\
\hline Murid & $\begin{array}{l}\text { Dalam SiBimBel, murid tidak begitu banyak } \\
\text { memiliki peran. Murid hanya dapat mengerjakan } \\
\text { kuis online. }\end{array}$ \\
\hline
\end{tabular}


Setiap use case yang ada pada SiBimBel dijabarkan menjadi diagram activity. Salah satu diagram activity yaitu untuk membuat soal kuis online seperti terlihat pada Gambar 2. Aktivitas tersebut hanya dapat dilakukan oleh guru. Terdapat dua pengambilan keputusan pada saat guru membuat soal, yang pertama adalah saat guru dihadapkan pada dua pilihan apakah ingin membuat soal apa tidak, yang kedua adalah saat guru dihadapkan dengan pilihan apakah guru ingin menambahkan gambar atau tidak pada soal tersebut.

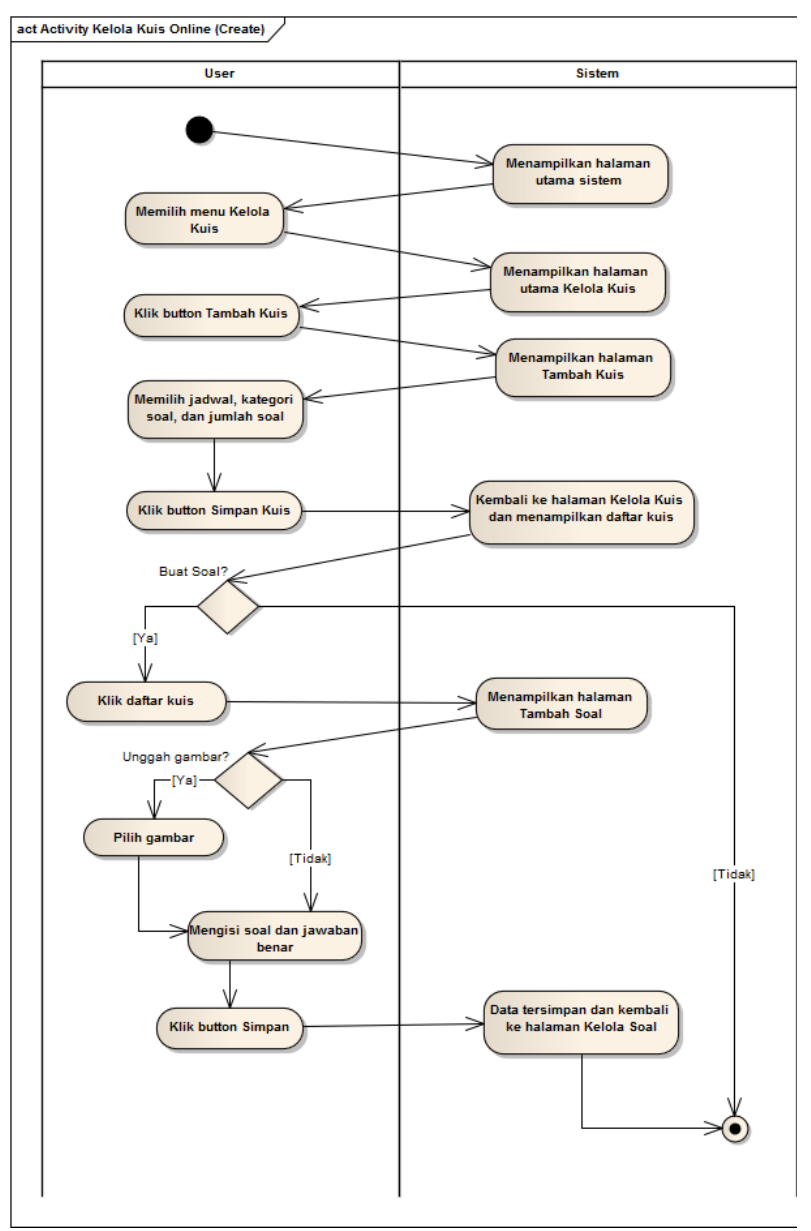

Gambar 2. Diagram Activity Membuat Soal

Selain diagram aktivitas, dihasilkan pula diagram Sequence. Diagram ini digunakan untuk menggambarkan skenario atau rangkaian langkah yang digunakan sebagai respon dari sebuah event untuk menghasilkan keluaran tertentu. Diawali dari apa saja yang memicu aktivitas tersebut, proses dan perubahan apa saja yang terjadi secara internal dan keluaran apa yang dihasilkan. Salah satu diagram sequence untuk SiBimBel terlihat pada Gambar 3. Terlihat user yaitu guru les, orangtua atau wali murid, dan murid untuk login ke dalam sistem. Perbedaan pada ketiga user tersebut hanya terletak pada penamaan boundary, control, dan method. Jika login sebagai orangtua atau wali murid maka nama boundary adalah activity home parents dan nama control adalah LoginParentsActivity dengan method doLoginParents, getOrtuID, dan getNamaOrtu. Jika login sebagai murid maka nama boundary adalah activity_home_student dan nama control adalah LoginStudentActivity dengan method doLoginMurid, getMuridID, dan getNamaMurid.

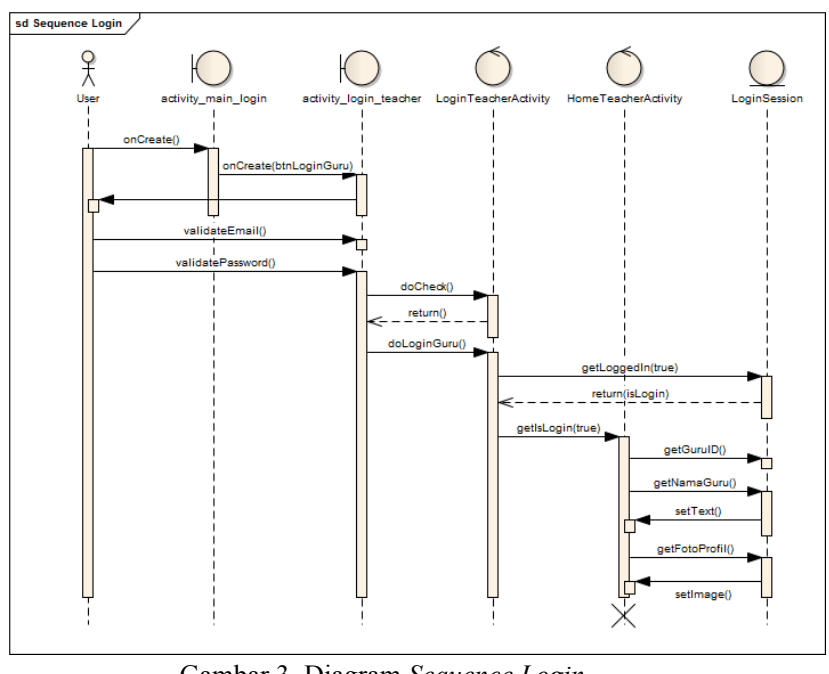

Gambar 3. Diagram Sequence Login

Class Diagram digunakan untuk menampilkan class pada suatu sistem yang digunakan. Class diagram dapat memberikan sebuah gambaran mengenai sistem maupun relasi-relasi yang terdapat pada sistem tersebut. Adapun class diagram untuk SiBimBel terlihat pada Gambar 4. Terdapat beberapa kelas yang merupakan turunan AppCompatActivity yaitu AbsenActivity, ProfileTeacherActivity, EditProfileTeacherActivity HomeTeacherActivity, StudentGrowthTeacher, StudentGrowthListTeacher, LoginTeacherActivity, ScheduleAjukan, SchedulePrepare, dan ScheduleDetailActivity. Kelas yang merupakan model seperti DataSchedule, DataScheduleMe, dan DataMyStudent.

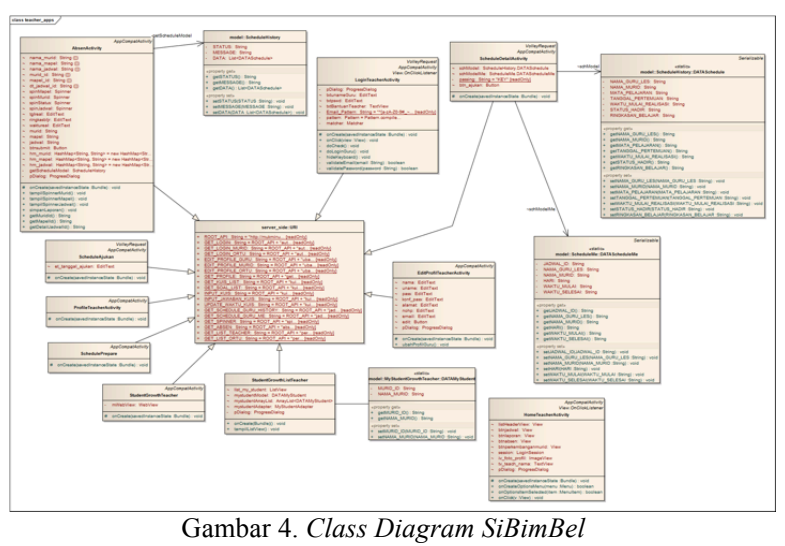




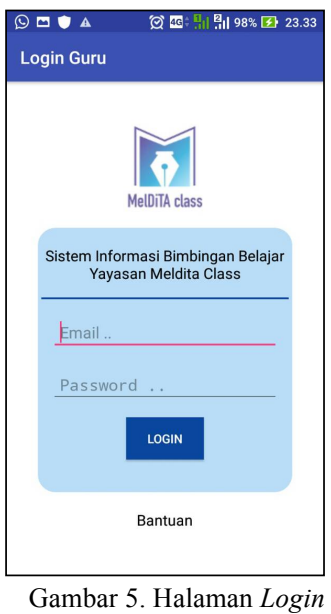

Gambar 5 merupakan tampilan halaman login. Pada halaman ini pengguna memasukkan email dan password yang sudah didaftarkan.

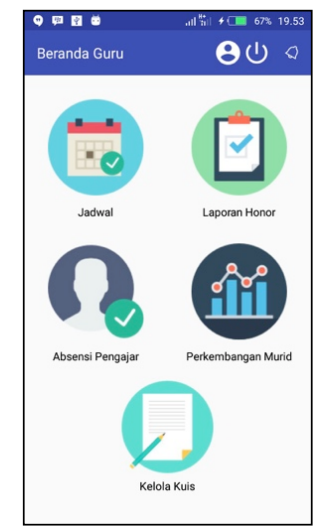

Gambar 6. Halaman Menu Guru Les

Gambar 6 merupakan halaman menu atau halaman utama guru les setelah melakukan login. Ada 5 menu yaitu jadwal, laporan honor, absensi guru, perkembangan murid, dan kelola kuis.

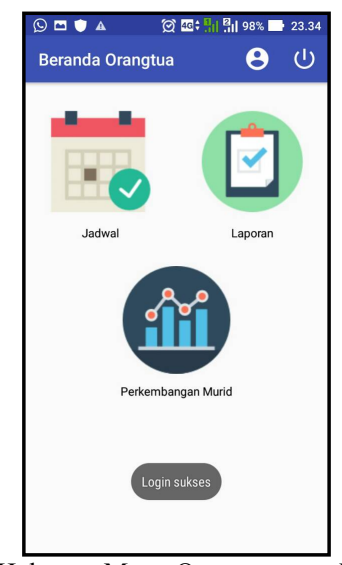

Gambar 7. Halaman Menu Orangtua atau Wali Murid

Gambar 7 adalah gambar halaman menu atau halaman utama orangtua atau wali murid setelah melakukan login. Ada 3 menu yaitu jadwal, laporan, dan perkembangan murid.

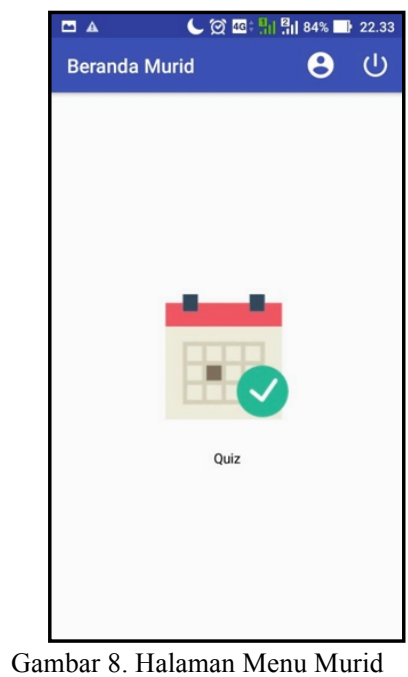

Gambar 8 merupakan gambar halaman menu atau halaman utama murid setelah melakukan login. Murid hanya memiliki satu menu atau satu fitur, yaitu mengerjakan kuis online.

Pengujian aplikasi dilakukan pada proses deployment menggunakan metode User Acceptance Testing (UAT). Pengujian yang dilakukan oleh pengguna atau civitas Meldita Class. Sebelum aplikasi diserahkan sepenuhnya, melalui pengujian UAT ini dilakukan uji kesesuaian apakah sistem sudah sesuai dengan kebutuhan bisnis atau belum.

TABEL 3. USER ACCEPTANCE TESTING

\begin{tabular}{|l|l|l|l|}
\hline Skenario Pengujian & Hasil Uji & $\begin{array}{l}\text { Jumlah } \\
\text { Populasi }\end{array}$ & $\begin{array}{l}\text { Perse } \\
\text { ntase }\end{array}$ \\
\hline $\begin{array}{l}\text { Ketiga aktor membuka } \\
\text { sistem }\end{array}$ & Sesuai & $\begin{array}{l}3 \text { Guru } \\
3 \text { Orangtua }\end{array}$ & $100 \%$ \\
\hline $\begin{array}{l}\text { Orangtua atau wali murid } \\
\text { dan guru les mengisi email } \\
\text { dan password sedangkan } \\
\text { murid mengisi username } \\
\text { dan password dengan data } \\
\text { yang benar dan valid. }\end{array}$ & Sesuai & $\begin{array}{l}3 \text { Guru } \\
3 \text { Orangtua }\end{array}$ & $100 \%$ \\
\hline $\begin{array}{l}\text { Guru les dan orangtua atau } \\
\text { wali murid melakukan } \\
\text { pencarian jadwal rutin. }\end{array}$ & Sesuai & 3 Guru & $100 \%$ \\
\hline $\begin{array}{l}\text { Guru les dan orangtua atau } \\
\text { wali murid melakukan } \\
\text { pencarian jadwal dengan } \\
\text { menginput tanggal dari } \\
\text { dan tanggal sampai. }\end{array}$ & Sesuai & 3 Guru & $100 \%$ \\
\hline $\begin{array}{l}\text { Orangtua atau wali murid } \\
\text { melakukan perubahan } \\
\text { jadwal setelah melakukan } \\
\text { pencarian terhadap jadwal } \\
\text { dengan mengisi tanggal } \\
\text { les dan alasannya. }\end{array}$ & Sesuai & 3 Orangtua & \\
\hline $\begin{array}{l}\text { Guru les menginput absen } \\
\text { sesuai dengan field yang } \\
\text { sudah disediakan sistem. }\end{array}$ & Sesuai & 3 Guru & $100 \%$ \\
\hline $\begin{array}{l}\text { Murid memilih kuis online } \\
\text { berdasarkan kategori kuis }\end{array}$ & Sesuai & 3 Murid & $100 \%$ \\
\hline
\end{tabular}


Tahapan akhir dari pengembangan aplikasi menggunakan metode GRAPPLE ialah penyebarannya setelah selesai dibuat. Penyebaran aplikasi dilakukan dengan cara mengunggah aplikasi ke Google Playstore sehingga dapat diunduh dan dipasang oleh pengguna.

\section{KESIMPULAN}

Berdasarkan hasil analisa, perancangan, dan implementasi yang sudah dilakukan sebelumnya, dapat diambil kesimpulan bahwa aplikasi SiBimBel untuk guru les, orangtua atau wali murid, serta murid telah berhasil dibuat dengan fitur yang berbeda-beda antara guru les, orangtua atau wali murid, serta murid.

Fitur Jadwal untuk mencari dan melihat jadwal serta mengajukan perubahan jadwal yang dapat digunakan oleh guru les dan orangtua atau wali murid. Fitur Laporan Honor hanya dapat digunakan oleh guru les, berfungsi untuk melihat jumlah honor yang didapat setiap bulannya. Fitur Absen berfungsi untuk mengisi absen atau laporan mengajar yang dapat diisi dan digunakan oleh guru les.

Fitur Laporan hanya dapat digunakan oleh orangtua atau wali murid, berfungsi sebagai melihat absen mengajar yang sudah diisi oleh guru les pada fitur absen serta memberikan umpan balik berupa rating dan komentar. Fitur Perkembangan Murid dapat digunakan oleh guru les dan orangtua atau wali murid, berfungsi sebagai melihat perkembangan murid setiap bulannya yang akan ditampilkan dalam bentuk grafik. Fitur Kelola Kuis hanya dapat digunakan oleh guru les, berfungsi untuk mengelola kuis online seperti membuat kuis online, menghapus soal kuis online, mengedit soal kuis online, menilai kuis online, serta menerbitkan atau publish soal tersebut yang nanti akan muncul pada sistem murid. Fitur Kuis Online yang hanya dapat digunakan oleh murid, berfungsi untuk mengerjakan soal-soal kuis online yang sudah dibuat oleh guru les sebagai sarana latihan murid sebelum menghadapi macam-macam ujian di sekolah seperti UAS, UTS, serta try out.
Aplikasi diuji menggunakan metode blackbox dan user acceptance testing. Hasil pengujian terhadap 9 responden, yaitu 3 orang guru les, 3 orang orangtua atau wali murid, dan 3 murid menyatakan aplikasi layak untuk dipakai oleh Yayasan Meldita Class.

Beberapa fitur yang bisa ditambahkan untuk pengembangan lebih lanjut diantaranya yaitu fitur melihat detail laporan pembayaran les bagi orangtua, serta pihak orangtua atau wali murid dan murid dapat melihat profil yayasan. Pengaturan waktu les yang sama bagi murid yang memiliki orangtua dan alamat rumah yang sama. Platform selain Android juga dapat dipertimbangkan untuk pengembangan berikutnya.

\section{REFERENSI}

[1] Mulyadi. Diagnosis Kesulitan Belajar dan Bimbingan terhadap Kesulitan Belajar Khusus. Jogjakarta: Nuha Litera, 2010.

[2] Safaat, Nazruddin. Android Pemrograman Aplikasi Mobile Smartphone dan Tablet PC. Bandung: Informatika, 2011.

[3] Taveekarn, Warit, Rukpatsorn Latthitham, Nuttawat Kittichareonjit, and Vasaka Visoottiviseth. FindMyTutor : An Android Application for Matching Students and Private Tutors. Third ICT International Student Project Conference Journal. 2014.

[4] Sakti, Ardhy Yuliawan Norma, Yusuf Priyandari, Muhammad Hisjam. Perancangan Sistem Informasi Manajemen Auditor Teknologi Pada Sistem Nasional Audit Teknologi (SNAT) Menggunakan Metode Grapple. Industrial Engineering Conference (ICE). 2016.

[5] Booch G., Maksimchuk RA, Engle MW, Young BJ, Conallen Jimm, Houston KA. 2007. Object-Oriented Analysis And Design With Applications Third Edition, Addison-Wesley, United States.

[6] A.S, Rosa, dan M. Shalahuddin. 2015. Rekayasa Perangkat Lunak Terstruktur dan Berorientasi Objek. Bandung: Informatika. 